A. R. HAJIPOUR*, F. REZAEI, Z. KHORSANDI* (ISFAHAN UNIVERSITY OF TECHNOLOGY, IRAN AND UNIVERSITY OF WISCONSIN, MADISON, USA)

$\mathrm{Pd} / \mathrm{Cu}$-Free Heck and Sonogashira Cross-Coupling Reaction by Co Nanoparticles Immobilized on Magnetic Chitosan as Reusable Catalyst

Green Chem. 2017, 19, 1353-1361.

\section{Heck and Sonogashira Reactions on Magnetic Cobalt Nanoparticles}

\section{Gategory}

Polymer-Supported

Synthesis

\section{Key words}

\section{chitosan}

Heck reaction

Sonogashira coupling

cobalt catalysis

nanoparticles

heterogeneous catalysis

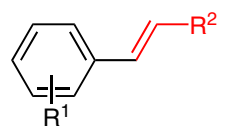

up to $92 \%$ yield (26 examples)

Selected examples:

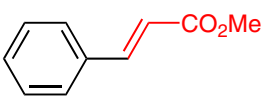

$88 \%$ yield $(X=I)$ $81 \%$ yield $(X=B r)$ $71 \%$ yield $(X=C l)$

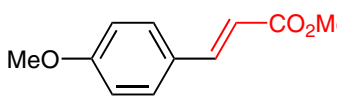

$92 \%$ yield $(X=I)$ $87 \%$ yield $(X=B r)$

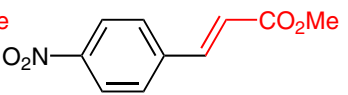

$79 \%$ yield $(X=B r)$
(1)

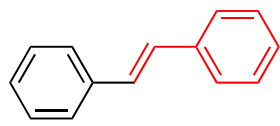

$75 \%$ yield $(X=I)$<smiles></smiles>

$(\mathrm{X}=\mathrm{I}, \mathrm{Br})$<smiles>C#Cc1ccccc1</smiles>

(1.1 equiv)

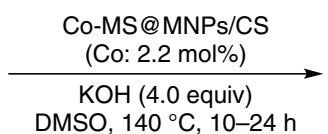

DMSO, $140{ }^{\circ} \mathrm{C}, 10-24 \mathrm{~h}$<smiles>C(#Cc1ccccp1)c1ccccc1</smiles>

up to $80 \%$ yield (15 examples)

Selected examples:

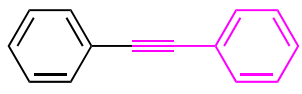

$72 \%$ yield $(X=1)$ $56 \%$ yield $(X=B r)$

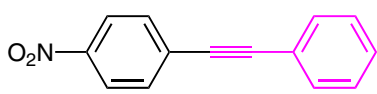

$80 \%$ yield $(X=I)$ $61 \%$ yield $(X=B r)$

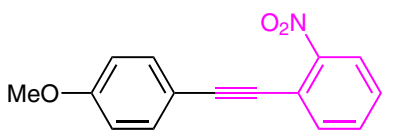

$61 \%$ yield $(X=B r)$
Significance: A magnetic, chitosan-supported, methyl salicylate-cobalt complex (Co-MS@MNPs/ CS) was prepared as shown in eq.1.Co-MS@MNPs/ CS catalyzed the Heck reaction of aryl halides with terminal olefins to give the corresponding internal alkenes in $\leq 92 \%$ yield (eq. 2, 26 examples). CoMS@MNPs/CS also promoted the Sonogashira reaction of aryl iodides or bromides with arylacetylenes to give the corresponding diarylacetylenes in $\leq 80 \%$ yield (eq. 3,15 examples).
Comment: The catalyst was characterized by means of FT-IR, TGA, EA, XRD, FE-SEM, SEMEDX, TEM, magnetization curve, and ICP analyses. In the Heck reaction of iodobenzene with methyl acrylate, the catalyst was recovered and reused four times without loss of its catalytic activity. 